17 Krupp LB, Mendelson WB, Friedman R. An overview of chronic fatigue syndrome. F Clin Psychiatry 1991;52:403-10.

18 Moldofsky $\mathrm{H}$. Non-restorative sleep and symptoms after a febrile illness in patients with fibrositis and chronic fatigue syndromes. If Rheumatol 1989;16(suppl 19):150-3.

19 Abbey SE, Garfinkel PE. Chronic fatigue syndrome and the psychiatrist. Can I Psychiatry 1990;35:625-33.

20 Kupfer DJ. Maintenance treatment in recurrent depression: current and future directions. The first William Sargent lecture. $\mathrm{Br}$ f Psychiatry 1992;161:309-16.

21 Reynolds CF, Shaw DH, Newton T, Coble PA, Kupfer DJ. EEG sleep in outpatients with generalised anxiety: a preliminary comparison with depressed outpatients. Psychiatry Res 1983;8:81-9.
22 Arriga F, Rosado P, Paiva T. The sleep of dysthymic patients: a comparison with normal controls. Biol Psychiatry 1990;27:649-56.

23 Neyta N, Horne JA. Effects of sleep extension and reduction on mood in healthy adults. Human Psychopharmacology 1990;6:173-88.

24 Myles WS. Sleep deprivation, physical fatigue and the perception of exercise intensity. Med Sci Sports Exerc 1985;17:580-4.

25 McMurray RG, Brown CF. The effect of sleep loss on high intensity exercise and recovery. Aviat Space Environ Med 1984;55:1031-5.

26 Mackie RR. Vigilance, theory, operational performance and physiological correlates. New York: Plenum Press, 1977.

(Accepted 18 February 1993)

\title{
Coronary artery surgery: are women discriminated against?
}

\author{
Mark Petticrew, Martin McKee, Jeremy Jones
}

\section{Abstract}

Objective-To determine whether the sex differences in access to cardiac surgery observed in the United States exist in the United Kingdom.

Design-Retrospective analysis of routinely collected data.

Setting-South West Thames and North West Thames regional health authorities.

Subjects-8564 patients discharged from hospital with a principal diagnosis of coronary heart disease in 1987-8 in South West Thames region and 15243 discharges in North West Thames region in 1990-1.

Main outcome measures-Performance of angiography or coronary artery bypass surgery.

Results-In all age groups and among patients with a principal diagnosis of either angina or chronic ischaemia men were significantly more likely than women to undergo revascularisation in both regions. Using multiple logistic regression to control for potential clinical and demographic confounders, the male to female odds ratio for revascularisation among all cases was 1.59 (95\% confidence interval 1.25 to 2.03 ) in South West Thames region and 1.47 $(1.32$ to 1.63$)$ in North West Thames region.

Conclusion-There appears to be a systematic difference in the treatment received by men and women in the United Kingdom. The reasons for this are uncertain.

\section{Introduction}

There is a growing body of evidence that women in the United States are less likely than men to receive treatment for certain conditions. For chronic renal failure women are $20 \%$ less likely to be placed on dialysis, ${ }^{1}$ and, once on a dialysis programme, they are up to $50 \%$ less likely to receive a transplant. ${ }^{24}$ For coronary artery disease women with positive results on radionuclide exercise tests are one tenth as likely to be referred for surgery, ${ }^{5}$ those admitted for coronary artery disease are less likely to undergo angiography or revascularisation, ${ }^{6-8}$ and when women are referred for surgery it is at a later stage in the disease. ${ }^{9}$ Nevertheless, once a woman has undergone angiography she is almost as likely as a man to proceed to surgery. ${ }^{8}$ Healy has described this phenomenon as the Yentl syndrome, in which a woman can achieve equality only by being "just like a man." She argues that this can be done by, for example, showing that she has severe coronary artery disease on angiography. ${ }^{10}$

We cannot assume that the same results would be found in the United Kingdom because of the differences between the British and American health systems. For example, while the United Kingdom's National Health Service provides free care for all, many United States insurance plans have reduced the level of cover for dependants, thus relatively disadvantaging children and non-working women. ${ }^{11}$ There may also be as yet unidentified cultural differences. ${ }^{12}$

We have examined whether sex differences exist in gaining access to treatment for coronary heart disease in the United Kingdom. To ensure that any observed difference is not simply the consequence of decisions made in a single institution or by an individual doctor we used two large sets of hospital data.

\section{Methods}

Retrospective analyses were performed for patients discharged from hospitals in 13 districts in the South West Thames region during 1987-8 and for patients discharged in 13 districts in North West Thames region in 1990-1. The data available included the age, sex, primary diagnosis, up to four secondary diagnoses, and up to three procedure codes for each patient in South West Thames region. In North West Thames region up to six secondary diagnoses and up to four procedures were coded.

Patients with a primary diagnosis of either myocardial infarction (ICD-9 code 410), angina (code 413), chronic ischaemia (codes $414 \cdot 0-9$ ), or chest pain (code 786.5) were selected from the databases for further analysis. This produced two groups of patients with a primary diagnosis of coronary heart disease, numbering 8564 patients in South West Thames region and 15243 patients in North West Thames region.

For these patients the male to female odds of revascularisation by either angioplasty (Office of Population Censuses and Surveys (fourth revision) (OPCS 4) codes K49.1-K49.3, K49.8, K49.9, K50.1$\mathrm{K} 50.3$, K50.8, $\mathrm{K} 50.9$ ) or coronary artery bypass surgery (codes $\mathrm{K} 40.1-\mathrm{K} 40.9$ to $\mathrm{K} 48.1-\mathrm{K} 48.9$ ) were calculated.

The male to female odds ratios were stratified by primary diagnosis, by age (ages 30-49, 50-69, 70-89, and, in North West Thames, $\geqslant 90$ years), by secondary diagnosis of congestive heart failure (ICD- 9 codes 428 , $428.0,428.1,428.9$ ), and by secondary diagnosis of diabetes mellitus (ICD-9 codes 250, 250.0 to 250.7, 250.9 ) to control as far as possible variables confounding the relation between sex and rate of revascularisation. Sex differences in the distribution of these characteristics are shown in table I. $\chi^{2}$ Tests and the $\chi^{2}$ test for trend were used to calculate differences between men and women in the distributions of these characteristics.

We then calculated male to female odds ratios, using multiple logistic regression models to control for the potential confounders described above, with age entered as a continuous variable; $95 \%$ confidence intervals for each of these strata were also calculated. 
Similar data analysis and stratification methods have been used to investigate sex differences in revascularisation in a United States dataset. ${ }^{\circ}$ All statistical procedures were carried out using SPSS- $\mathrm{X}^{13}$ and EGRET $^{14}$ statistical software.

\section{Results}

Data on 8564 episodes in South West Thames and 15243 episodes in North West Thames were analysed among the patients concerned $36 \%$ and $35 \%$ respectively were women. Summary statistics are shown in table I. Women were significantly older than men in both regions $(p=0.001$ and $p<0.0001$ for South West Thames and North West Thames regions respectively) and more likely to have a principal diagnosis of chest pain $(p=0.003, p<0.0001)$. They were less likely to have a principal diagnosis of chronic ischaemia $(p=0.001, p<0.0001)$ but more likely to have a secondary diagnosis of congestive heart failure $(p=0.001, p<0.0001)$. In North West Thames only women were more likely to have a primary diagnosis of myocardial infarction $(p=0.00002)$.

In all age groups and among patients with a principal diagnosis of either angina or chronic ischaemia men were significantly more likely than women to undergo revascularisation in both regions (table II). The numbers of patients undergoing revascularisation with a principal diagnosis of myocardial infarction or chest pain were too small for meaningful analysis in South West Thames. In North West Thames, however, men with a principal diagnosis of myocardial infarction were significantly more likely to undergo revascularisation. When multiple logistic regression was used to control for the potential clinical and demographic confounders listed in table I the male to female odds ratios for revascularisation among all cases were 1.59 (95\% confidence interval 1.25 to 2.03 ) in South West

TABLE I-Principal diagnoses, ages, and secondary diagnoses of men and women discharged from hospitals in two NHS regions

\begin{tabular}{|c|c|c|c|c|}
\hline \multirow[b]{2}{*}{ Characteristic } & \multicolumn{2}{|c|}{ South West Thames } & \multicolumn{2}{|c|}{ North West Thames } \\
\hline & Men & Women & Men & Women \\
\hline $\begin{array}{l}\text { No of discharges } \\
\text { Principal diagnosis (\%): }\end{array}$ & 5450 & 3114 & 9863 & 5380 \\
\hline Myocardial infarction & 31.4 & $33 \cdot 4$ & $32 \cdot 9$ & $36 \cdot 3$ \\
\hline Angina & $24 \cdot 2$ & $24 \cdot 5$ & $20 \cdot 5$ & 21.5 \\
\hline Chronic ischaemia & $21 \cdot 6$ & $16 \cdot 5$ & $28 \cdot 0$ & $18 \cdot 2$ \\
\hline Chest pain & $22 \cdot 8$ & $25 \cdot 6$ & $18 \cdot 7$ & 23.9 \\
\hline \multicolumn{5}{|l|}{ Age group (\%): } \\
\hline $30-49$ & $16 \cdot 8$ & $7 \cdot 0$ & $15 \cdot 8$ & 8.9 \\
\hline $50-69$ & $51 \cdot 1$ & $35 \cdot 5$ & 55.4 & 37 \\
\hline $70-89$ & $32 \cdot 1$ & 57.5 & $26 \cdot 6$ & $48 \cdot 8$ \\
\hline$\geqslant 90$ & - & - & 0.8 & $3 \cdot 7$ \\
\hline \multicolumn{5}{|l|}{ Secondary diagnosis (\%): } \\
\hline Congestive heart failure & $4 \cdot 4$ & $7 \cdot 6$ & $2 \cdot 3$ & 8.5 \\
\hline Diabetes mellitus & $4 \cdot 7$ & $5 \cdot 6$ & $7 \cdot 0$ & $7 \cdot 8$ \\
\hline
\end{tabular}

Thames and 1.47 (95\% confidence interval 1.32 to 1.63 ) in North West Thames.

\section{Discussion}

These results suggest that in the United Kingdom women are less likely than men to receive surgical treatment for coronary heart disease, even after potential confounding variables have been taken into account. Firstly, however, certain problems affecting any analysis of United Kingdom hospital data require examination.

The accuracy of hospital data has often been questioned, ${ }^{1516}$ although it has also been argued that the problem is overstated because researchers are more likely to submit papers identifying a problem. ${ }^{17}$ While we do not claim to have identified all angioplasties and bypass operations undertaken within these regions, it is difficult to see how a systematic difference in data capture would occur between the sexes. Our data covered only treatment in National Health Service hospitals, missing for example the $25 \%$ of operations undertaken in the private sector in South West Thames. ${ }^{18}$ If anything, one would expect this omission to increase the size of the difference because men have a higher level of private insurance coverage.

There may be sound clinical reasons for our findings. ${ }^{6}$ Different rates could be justified if coronary artery disease were more severe in men. This could be due to the presence of confounding variables such as differences in severity or cardiac function that are not identified on routine discharge data. ${ }^{19}$ The existence of such differences is not supported by evidence that women are equally likely to die after a myocardial infarction when allowance is made for their older age,,$^{20}$ but, even if such existences do exist, they are equally likely to be due to differences in referral as a cause of them. ${ }^{8}$

Surgeons may consider that surgery in women is either less effective or carries a greater risk. This is supported by some studies in the 1970 s and early 1980 s that found that women had a higher perioperative mortality ${ }^{21} 22$ and others showing that a greater proportion of men were asymptomatic after surgery. ${ }^{23}$ It has been argued that these findings result from greater technical problems, including narrower coronary arteries, in women, although some earlier studies found no difference. ${ }^{24}$ Moreover, recent work has shown that observed differences can be explained entirely by the referral of women for surgery at a later stage in their disease and with a correspondingly lower level of cardiac function. ${ }^{25}$ Furthermore, long term survival for men and women is the same. ${ }^{26}$

A third possible clinical explanation is that women admitted with ischaemic symptoms may be less likely

TABLE II-Percentages of men and women undergoing revascularisation and male to female odds ratios, with stratification for confounding variables

\begin{tabular}{|c|c|c|c|c|c|c|}
\hline & \multicolumn{3}{|c|}{ South West Thames } & \multicolumn{3}{|c|}{ North West Thames } \\
\hline & $\begin{array}{c}\% \text { (No) } \\
\text { among men }\end{array}$ & $\begin{array}{c}\%(\mathrm{No}) \\
\text { among women }\end{array}$ & $\begin{array}{l}\text { Odds ratio } \\
(95 \% \mathrm{CI})\end{array}$ & $\begin{array}{c}\%(\mathrm{No}) \\
\text { among men }\end{array}$ & $\begin{array}{c}\%(\text { No) } \\
\text { among women }\end{array}$ & $\begin{array}{l}\text { Odds ratio } \\
(95 \% \mathrm{CI})\end{array}$ \\
\hline \multicolumn{7}{|l|}{ Principal diagnosis: } \\
\hline Myocardinal infarction & $0.7(12)$ & $0.1(1)$ & $7.28(1.07 \text { to } 311.61)^{\star}$ & $1.9(60)$ & $0.8(16)$ & $2.29(1.27$ to $4 \cdot 16)$ \\
\hline Angina & $10.4(137)$ & $5 \cdot 5(42)$ & $1.99(1.37$ to 2.89$)$ & $7.5(152)$ & $3.4(39)$ & 2.34 (1.61 to 3.42$)$ \\
\hline Chronic ischaemia & $18.9(222)$ & $10.7(55)$ & $1.94(1.40$ to 2.70$)$ & $32 \cdot 1(885)$ & $21 \cdot 5(210)$ & $1.73(1.45$ to 2.07$)$ \\
\hline \multirow{2}{*}{\multicolumn{7}{|c|}{ Age (years) $t:$}} \\
\hline & & & & & & \\
\hline $30-49$ & $7 \cdot 3(67)$ & $1 \cdot 8(4)$ & $4.2(1.54$ to 16.03$)$ & $12.5(194)$ & $6 \cdot 1(29)$ & $2.20(1.44$ to 3.38$)$ \\
\hline $50-69$ & $9 \cdot 2(257)$ & $6.6(73)$ & $1.44(1.09$ to 1.90$)$ & $14.6(799)$ & $9.9(198)$ & $1.55(1.31$ to 1.84$)$ \\
\hline $70-89$ & $3 \cdot 1(54)$ & $1 \cdot 2(21)$ & $2.68(1.57$ to 4.61$)$ & $4.0(106)$ & $1.4(37)$ & $2.94(1.98$ to 4.39$)$ \\
\hline$\geqslant 90$ & & & & $2 \cdot 7(2)$ & $0.5(1)$ & $5.44(0.37 \text { to } 156.8)^{\star}$ \\
\hline \multicolumn{7}{|l|}{ Congestive heart failure: } \\
\hline Yes & $0.8(2)$ & $0(0)$ & * & $2 \cdot 0(11)$ & $0.7(3)$ & $3.05(0.78 \text { to } 14.01)^{\star}$ \\
\hline No & $7 \cdot 2(376)$ & $3.4(98)$ & $2.2(1.75$ to 2.78$)$ & $11.9(1092)$ & $5.4(263)$ & $2.36(2.04$ to 2.72$)$ \\
\hline \multicolumn{7}{|l|}{ Diabetes mellitus: } \\
\hline Yes & $4 \cdot 3(11)$ & $1.7(3)$ & $2.54(0.66$ to 14.35$)$ & $13.7(93)$ & $8.2(34)$ & $1.78(1.15$ to 2.75$)$ \\
\hline No & $7 \cdot 1(367)$ & $3 \cdot 2(95)$ & $2.28(1.8$ to 2.89$)$ & $11 \cdot 2(1010)$ & $4 \cdot 8(232)$ & 2.52 (2.17 to 2.93$)$ \\
\hline
\end{tabular}

*Few cases. $\quad$ T Two men and one woman in North West Thames had no age recorded and are not included in these age groups. 
to have coronary artery disease. In the case of chest pain this is supported by the finding in the coronary artery surgery study that $50 \%$ of women with chest pain referred for angiography had minimal or no coronary artery narrowing compared with $17 \%$ of men. ${ }^{27}$ Against this, however, is the finding by Ayanian that the difference in the likelihood of surgery is present even among those who have had a myocardial infarction. ${ }^{6}$ We also found this in our study.

We believe that none of these suggestions satisfactorily explains the observed differences. The true explanation is more likely to arise from the system of beliefs that leads to women with subsequently proved ischaemic heart disease being referred for angiography much less often than men, despite their greater level of disability. ${ }^{8}$ This is consistent with a growing body of evidence from other areas of medicine, such as that on the treatment of chronic renal failure ${ }^{1-4}$ and a British study that found that women wait longer for pacemaker implantation. ${ }^{28}$ Our findings suggests that there is systematically greater access to surgery for coronary heart disease for men than for women.

This systematic difference may be mediated through the attitudes of doctors or patients or both. Doctors may discriminate against women on clinical grounds or they may place less value on the benefit that would be gained by women. They may be influenced by the way in which many studies of prevention and treatment of cardiovascular diseases have been conducted exclusively in men. ${ }^{10} \mathrm{~A}$ third factor exists in the United States, where the gynaecologists used by many women as primary physicians may be less aware of the potential benefits of surgery. ${ }^{29}$ This is clearly not the case in the United Kingdom.

Men and women may have differing views about the risks and benefits of surgery. Ayanian has argued from evidence that women are less likely to return to work after a myocardial infarction ${ }^{30}$ that they may also be more willing to adapt their lifestyles to avoid surgery. ${ }^{6}$ Women are less likely to accept an offer to take part in a cardiac rehabilitation programme after myocardial infarction $^{31}$ and more likely to leave such a programme prematurely. ${ }^{32}$

A caveat remains. If there really is systematically better access to surgery for men than for women it does not necessarily imply that women are being disadvantaged. The differences could be a result of overtreatment of men rather than undertreatment of women. ${ }^{33}$ This explanation is much less likely to apply in the United Kingdom, where the rate of cardiac surgery is substantially lower than in the United States, but better evaluative research is required.

This paper provides evidence for a systematic difference in the treatment received by men and women in the United Kingdom. The underrepresentation of women in evaluative studies has been addressed in the United States by the establishment of the office of research on women's health within the National Institutes of Health. ${ }^{10}$ Perhaps it is time to tackle this in the United Kingdom as well.
1 Kjellstrand CM, Logan GM. Racial, sexual and age inequalities in chronic dialysis. Nephron 1987;45:257-63.

2 Brogan D, Tuttle P. Transplantation and the Medicare end-stage renal disease programme. N Engl f Med 1988;319:55.

3 Held PJ, Pauly MV, Bovberg RR, Newmann J, Salvatierra O. Access to kidney transplantation. Has the United States eliminated income and racia differences. Arch Intern Med 1988;148:2594-600.

4 Kjellstrand CM. Age, sex and race inequality in renal transplantation. Arch Intern Med 1988;148:1305-9.

5 Tobin JN, Wassertheil-Smoller S, Wexler JP, Heingart RM, Budner N, Lense L, et al. Sex bias in considering coronary bypass surgery. Ann Intern Med 1987;107:19-25.

6 Ayanian JZ, Epstein AM. Differences in the use of procedures between women and men hospitalized for coronary artery disease. N Engl f Med 1991;325: 221-5.

7 Foster DA, Gillette MK, McNeill DN, Collins AM. Is there sex bias in the management of coronary artery disease? N Engl $\mathcal{3}$ Med 1992;326:570-1.

8 Steingart RM, Packer M, Hamm P, Coglianese ME, Gersh B, Geltman EM, et al. Sex differences in the management of coronary artery disease. $N$ Engl 7 Med 1991;325:226-30.

9 Khan SS, Nessim S, Gray R, Czer LS, Chaux A, Matloff J. Increased mortality of women in coronary artery bypass surgery; evidence for referral bias. Ann Intern Med 1990;112:561-7.

10 Healy B. The Yentl syndrome. N Engl f Med 1991;325:274-7.

11 Health and the uninsured. Washington DC: Congressional Research Service, Library of Congress. May 1988.

12 Payer L. Medicine and culture. London: Gollancz, 1989.

13 SPSS- $X$ data analysis system, Release 4.0. Chicago: SPSS Inc.

14 Egret: epidemiological graphics estimation and testing package. Statistics and Epidemiology Research Corporation, Seattle: Statistics and Epidemiology Research Corporation, 1990.

15 Mukheriee AK, Leck I, Langley FA, Ashcroft C. The completeness and accuracy of health authority and cancer registry records according to a study of ovarian neoplasms. Public Health 1991;105:69-78.

16 Rees JL. Accuracy of hospital activity analysis data in estimating the incidence of proximal femoral fracture. $B M 7$ 1982;284:1856-7.

17 Sellar C, Goldacre MJ, Hawton K. Reliability of routine hospital data on poisoning as measures of deliberate self poisoning in adolescents. f Epidemiol Community Health 1990;44:313-5.

18 Marber M, McRae C, Joy M. Delay to invasive investigation and revascularisation for coronary heart disease in South West Thamęs region: a two tier system? BMF 1991;302:1189-91.

19 Poses RM, Smith WR, Schmitt BP. Is there sex bias in the management of coronary artery disease? $\mathrm{N}$ Engl f Med 1992;326:570

20 Dittrich H, Gilpin E, Nicod P, Cali G, Henning H, Ross J. Acute myocardial infarction in women: influence of gender on mortality and prognostic variables. Am f Cardiol 1988;62:1-7.

21 Sheldon WC, Ricon G, Pichard AD, Razavi M, Cheanvechai C, Loop FD. Surgical treatment of coronary artery disease: pure graft operations with a study of 741 patients followed 3-7 years. Prog Cardiovasc Dis 1975;18: study of 74

22 Kennedy JW, Kaiser GC, Fisher LD, Fritz JK, Myers W, Mudd JG, et al. Clinical and angiographic predictors of operative mortality from the collaborative study in coronary artery surgery (CASS). Circulation 1981;63: 793-802.

23 Douglas JS, King SB, Jones EL, Craver JM, Bradford JM, Hatcher CR. Reduced efficacy of coronary bypass surgery in women. Circulation 1981;64:II-1 1-6.

24 Tyras DH, Barner HB, Kaiser GC, Codd JE, Laks H, Willman VL. Myocardial revascularisation in women. Ann Thorac Surg 1978;25:449-53.

25 Khan SS, Nessim S, Gray R, Czer LS, Chaux A, Matloff J. Increased mortality of women in coronary artery bypass surgery; evidence for referral bias. Ann Intern Med 1990;112:561-7.

26 Eaker ED, Kronmal R, Kennedy JW, Davis K. Comparison of the long-term, postsurgical survival of men and women in the coronary artery surgery study (CASS). Am Heart f 1989;117:71-81.

27 Kennedy JW, Killip T, Fisher LD, Alderman EL, Gillespie MJ, Monk MB. The clinical spectrum of coronary artery disease and its surgical and medical management, 1974-1979. The coronary artery surgery study. Circulation 1982;66(suppl 3):16-23.

28 Mackintosh AF, Boyle RM. Reasons for delay in permanent pacemaker insertion. $\mathcal{F} R$ Coll Physicians Lond 1986;20:220-1.

29 Kasserbaum DG. Is there sex bias in the management of coronary artery disease? $N$ Engl f Med 1992;326:571.

30 Chirikos TN, Nickel JL. Work disability from coronary heart disease in women. Women and Health 1984;9:55-74.

31 McGee HM, Horgan JH. Cardiac rehabilitation programmes: are women less likely to attend? $B M M^{2}$ 1992:305:283-4.

32 Oldridge MB, Lasalle D, Jones NL. Exercise rehabilitation of female patients with coronary heart disease. Am Hear f 1980;338:1366-7.

33 Brook RH, Kosecoff JB, Park RE, Chassin MR, Winslow CM, Hampton JR. Diagnosis and treatment of coronary artery disease: comparison of doctors' attritudes in the USA and the UK. Lancet 1988;i:750-3.

(Accepted 16 February 1993) 